\title{
COMPARISON OF ADRENALINE AND SALBUTAMOL NEBULIZATION IN TREATMENT OF CHILDREN WITH BRONCHIOLITIS.
}

1. MBBS, FCPS (Ped)

Senior Registrar

Department of Paediatric Medicine

Avicenna Medical College Lahore.

2. MBBS, FCPS (Ped), MCPS (Ped)

Professor

Department of Paediatric Medicine

Avicenna Medical College Lahore.

3. MBBS, FCPS (Ped)

Senior Registrar

Department of Paediatric Medicine

Avicenna Medical College Lahore.

4. MBBS, FCPS (Ped)

Senior Registrar

Department of Paediatric Medicine

Azra Naheed Medical College Lahore.

5. MBBS, FCPS (Ped)

Senior Registrar

Department of Paediatric Medicine

Avicenna Medical College Lahore.

6. MBBS, FCPS (Ped)

Senior Registrar

Department of Paediatric Medicine

Avicenna Medical College Lahore.

Correspondence Address:

Dr. Shehla Usman

House No. 149, Block-B T \&T

Aabpara Cooperative Housing Society,

Raiwind Road Lahore.

flik2035@gmail.com

Article received on:

24/11/2018

Accepted for publication:

15/03/2019

Received after proof reading:

$28 / 08 / 2019$
Shehla Usman', Aneela Zareen ${ }^{2}$, Aimun Gillani ${ }^{3}$, Ammara Kaleem $^{4}$, Mohsin Ali ${ }^{5}$, Hussan Ali Sarwar6

ABSTRACT... Background: Bronchiolitis is an acute inflammation of bronchioles that can be severe enough to require admission in intensive care unit. There are multiple modalities used for treatment of bronchiolitis. The objective of this study was to compare the response of adrenaline and salbutamol nebulization in terms of clinical improvement and duration of hospital stay. Study Design: Randomized controlled trial. Setting: Pediatrics Department of Avicenna Medical College and Hospital, Lahore. Period: March 2018 to October 2018. Methods: Total 66 patients with 33 in each group between ages of 2-months to 3-years admitted with the diagnosis of bronchiolitis, were included in the study. Children in the group 1 were patients treated with salbutamol nebulization $0.15 \mathrm{mg} / \mathrm{kg}$ with $3 \mathrm{ml}$ normal saline every six hourly. Children in the group 2 received adrenaline nebulization $0.1 \mathrm{ml} / \mathrm{kg}$ of $1: 1000$ dilutions with $3 \mathrm{ml}$ normal saline every six hourly. Both the groups were given similar supportive management that included oxygen therapy, intravenous fluids, and antipyretics. Data was collected in the form of age, gender, heart rate, respiratory rate, $\mathrm{SpO}^{2}$ and RDAl score at admission, $6 \mathrm{hr}, 24 \mathrm{hr}$ and $48 \mathrm{hr}$ after admission, duration of hospital stay and duration of oxygen therapy. Results: Out of 66 patients, $38(57.6 \%)$ were male and $28(42 \%)$ were female. The mean with standard deviation of age in months was $20.45 \pm 12.9$ in salbutamol group and $16.7 \pm 12.3$ in adrenaline group ( $p$ value $=0.23$ ). Mean with standard deviation of weight of patients was $9.7+3.5$ in salbutamol group and $8.9 \pm 3.3$ in adrenaline group $(p$ value $=0.34$ ). Regarding the duration of hospital stay the mean and standard deviation of hospital stay was $4.2 \pm 0.9$ in salbutamol group and $3.9 \pm$ 1 in adrenaline group with $p$ value 0.016 . Mean and standard deviation of duration of oxygen therapy was $1.05+0.7$ in salbutamol group and $0.9+0.4$ in adrenaline group with $p$ value 0.42 . There was no significant difference in the values of RDAl, heart rate, respiratory rate, $\mathrm{SPO}^{2}$ at admission and subsequently after $6 \mathrm{hrs}, 24 \mathrm{hrs}$, and $48 \mathrm{hrs}$. Conclusion: We concluded that there was a significant reduction in duration of hospital stay in patients who received adrenaline nebulization then those nebulized with salbutamol. RDAl scores in the initial 48 hours in both the groups were improved in successive readings, but there was no significant difference in RDAI scores between the two groups recorded at different time intervals.

Key words: $\quad$ Adrenaline, Bronchiolitis, Hospital Stay, Salbutamol.

Article Citation: Usman S, Zareen A, Gillani A, Kaleem A, Ali M, Sarwar HA. Comparison of Adrenaline and Salbutamol nebulization in treatment of Children with Bronchiolitis. Professional Med J 2019; 26(9):1434-1439.

DOI: 10.29309/TPMJ/2019.26.09.1537

\section{INTRODUCTION}

The term bronchiolitis is used for acute inflammation of the bronchioles that leads to edema and necrosis of the small airways as well as increased mucus production. ${ }^{1}$ Bronchiolitis occurs in children less than two years of age and respiratory syncytial virus is the commonest causative organism associated with bronchiolitis. ${ }^{2}$ Bronchiolitis accounts for $60 \%$ of the total cases of lower respiratory tract infections occurring during the first year of life and early childhood. It has been stated in the literature that bronchiolitis is a cause of hospitalization in 32 percent of infants and children admitted due to lower respiratory tract diseases. ${ }^{3}$ Majority of children suffering from bronchiolitis have only mild disease that is self limiting but in some cases the disease can be severe enough to require admission in the intensive care unit. Bronchiolitis is mainly diagnosed on clinical findings; supportive investigations as well as scoring system named RDAl (respiratory distress assessment 
instrument) are used for establishing severity of disease and treatment modalities to be used. ${ }^{4}$ Bronchiolitis affects a significant proportion of the population and is linked to further development of asthma in that population. ${ }^{5}$ In this disease, the small airways in the lungs become inflamed and filled with debris. ${ }^{6}$

The treatment of bronchiolitis mainly involves supportive management like suctioning of the secretions, encouragingfeeding, and maintenance of hydration. There is also recommendation of oxygen therapy for children presenting with low oxygen saturation. Other treatment strategies include bronchodilators, corticosteroids, and nebulized hypertonic saline, although there are no specific recommendations for their use. ${ }^{1}$ It has been mentioned in literature that adrenaline reduces mucosal swelling, giving it an edge over the $\beta 2$-adrenergic agonists; adrenaline also leads to improvement of symptoms and a reduction in the need for hospitalization in outpatients with acute bronchiolitis. Among in patients, however, inhaled adrenaline has not been found to reduce the length of the hospital stay. ${ }^{7}$ Regarding safety profile of adrenaline, nebulized adrenaline has been described as well tolerated, less expensive and safe drug of choice in diseases like croup, angioedema, bronchiolitis and post-extubation stridor. ${ }^{8}$ For most infants with viral bronchiolitis the course of illness does not progress beyond a mild, self-limiting illness and thus testing for RSV or other respiratory viruses is of limited clinical value. ${ }^{9}$

There are studies done in the past regarding the effectiveness of nebulized adrenaline and salbutamol in management of infants and children presenting with bronchiolitis, but the results are contradicting and no definite conclusion can be drawn. According to a study performed by Mohammad RM et al, epinephrine was more effective in terms of decreased hospital stay and reduction of RDAl score than salbutamol. ${ }^{3}$ However, Adhikari et al concluded in their study that patients of acute bronchiolitis experienced similar decline in RDAl scores whether they were nebulized with salbutamol or adrenaline. ${ }^{4}$ In another study by Sireesha $S$ et al, when they compared salbutamol with the adrenaline in relieving the distress and wheezing there was no statistically significant benefit of one over the other. $^{10}$

Bronchiolitis is a very common illness in young infants and children and different treatment modalities are used for its management. There are limited studies for further treatment options that can have better outcome, early recovery and discharge of patients. This study is aimed at determining whether there is any difference in the outcome of patients of bronchiolitis treated with adrenaline as compared to salbutamol.

\section{MATERIALS AND METHODS}

The study design was randomized controlled trial. This study was conducted in pediatrics department of Avicenna Medical College and Hospital, Lahore, from March 2018 to October 2018. Sample size was calculated to be 66 with 33 in each group with confidence interval 95\%, power $80 \%$, from Open Epi, Version 3, open source calculator-SS Mean, by keeping mean and standard deviation $3.7 \pm 1.1$ in salbutamol receiving group and $3 \pm 0.9$ in epinephrine receiving group. ${ }^{3}$ All infants and children between age of 2 months to 2 years admitted with the diagnosis of bronchiolitis, with an initial RDAl score of 5 or more at the time of admission, were included in the study; informed consent was taken from their parents. Children with history of Chronic Lung pathology (Cystic Fibrosis, Primary ciliary dyskinesia, congenital lobar emphysema, diaphragmatic hernia), history of prematurity (born before complete 37-weeks of gestation from LMP), with any congenital malformation (Congenital syndromes, Gastrointestinal or lung defects), with underlying congenital heart disease, or having pneumonia (from chest radiogram) were excluded from the study. All selected 66 patients were assigned to two groups, each having 33 patients, by lottery method. Children in the group 1 were patients treated with salbutamol nebulization $0.15 \mathrm{mg} / \mathrm{kg}$ with $3 \mathrm{ml}$ normal saline every six hourly. Children in the group 2 received adrenaline nebulization $0.1 \mathrm{ml} / \mathrm{kg}$ of $1: 1000$ dilutions with $3 \mathrm{ml}$ normal saline every six hourly. Both the groups were given similar supportive 
management that included oxygen therapy, intravenous fluids, and antipyretics. Data was collected in predesigned proformas in the form of age, gender, heart rate, respiratory rate, $\mathrm{SpO}^{2}$ and RDAl score at admission, 6hr, $24 \mathrm{hr}$ and 48hr after admission. Duration of hospital stay and oxygen therapy was also noted.

Data was analyzed using SPSS version 20 and $P$ value less than 0.05 was considered significant. Quantitative variables like RDAl, age, respiratory rate, heart rate, duration of hospital stay and duration of oxygen requirement were expressed as mean and standard deviation, and qualitative variables like gender were expressed as frequency.

\section{RESULTS}

Our total sample consisted of 66 patients, 33 in each group, out of which $38(57.6 \%)$ were male and $28(42 \%)$ were female. The mean with standard deviation of age in months and weight in $\mathrm{kg}$ was comparable in both groups (Table-I\&II).

\begin{tabular}{|c|c|c|}
\hline \multicolumn{3}{|c|}{ Mean age (months) } \\
\hline Salbutamol & Epinephrine & P-Value \\
\hline $20.4545 \pm 12.98$ & $16.72 \pm 12.3$ & 0.236 \\
\hline Table-I. Mean and standard deviation of age \\
(in months) in both groups
\end{tabular}

Table-II. Mean and standard deviation of weight $(\mathbf{k g})$ of patients in both groups

Regarding the duration of hospital stay the mean and standard deviation of hospital stay was $4.2 \pm$ 0.9 in salbutamol group and $3.9 \pm 1$ in adrenaline group with a $P$ value 0.016 that was a significant difference (Table-III).

\begin{tabular}{|c|c|c|}
\hline \multicolumn{3}{|c|}{ Duration of Hospital Stay } \\
\hline $\begin{array}{c}\text { Salbutamol } \\
\text { Group }\end{array}$ & $\begin{array}{c}\text { Adrenaline } \\
\text { Group }\end{array}$ & P Value \\
\hline $4.2 \pm 0.96$ & $3.9 \pm 1$ & 0.016 \\
\hline
\end{tabular}

The difference between the Mean and standard deviation of duration of oxygen therapy between the two groups was found to be insignificant (Table-IV). The difference between the values of RDAl scores recorded at various time intervals after admission was also insignificant. (Table-V)

\begin{tabular}{|c|c|c|}
\hline \multicolumn{3}{|c|}{ Duration of Oxygen Therapy } \\
\hline $\begin{array}{c}\text { Salbutamol } \\
\text { Group }\end{array}$ & $\begin{array}{c}\text { Adrenaline } \\
\text { Group }\end{array}$ & P-Value \\
\hline $1.05 \pm 0.79$ & $0.92 \pm 0.416$ & 0.12 \\
\hline
\end{tabular}

Table-IV. Mean and standard deviation of duration of oxygen therapy (in Days) in both groups

\begin{tabular}{|l|c|c|c|}
\hline \multicolumn{1}{|c|}{ RDAl } & Salbutamol & Adrenaline & P value \\
\hline Admission & $8.4 \pm 1.9$ & $8.4 \pm 1.8$ & 1.0 \\
\hline $6 \mathrm{Hrs}$ & $6.6 \pm 1.5$ & $6.5 \pm 1.5$ & 0.93 \\
\hline $24 \mathrm{Hrs}$ & $5.0+1.9$ & $4.3+1.3$ & 0.128 \\
\hline $48 \mathrm{Hrs}$ & $2.4 \pm 2$ & $1.6 \pm 1.6$ & 0.07 \\
\hline
\end{tabular}

Table-V. Mean and standard deviation of RDAI Score at Admission, $6 \mathrm{Hrs}, 24 \mathrm{Hrs}$, $48 \mathrm{Hrs}$ in both groups The values of heart rate, respiratory rate, and $\mathrm{SPO}^{2}$ at admission, after $6 \mathrm{hrs}, 24 \mathrm{hrs}$, 48hrs were also noted as given in the Table-VI,VII, VIII.

\begin{tabular}{|l|c|c|c|}
\hline $\begin{array}{c}\text { Respiratory } \\
\text { Rate }\end{array}$ & $\begin{array}{c}\text { Salbutamol } \\
\text { Group }\end{array}$ & $\begin{array}{c}\text { Adrenaline } \\
\text { Group }\end{array}$ & P-value \\
\hline Admission & $52.7 \pm 4.3$ & $51.1 \pm 4.6$ & 0.15 \\
\hline $6 \mathrm{Hrs}$ & $48.6 \pm 5.3$ & $46.4 \pm 4.2$ & 0.06 \\
\hline $24 \mathrm{Hrs}$ & $42.7 \pm 6.1$ & $40.6 \pm 4.2$ & 0.09 \\
\hline $48 \mathrm{Hrs}$ & $39.7 \pm 6.0$ & $38.3 \pm 4.2$ & 0.18 \\
\hline
\end{tabular}

Table-VI. Mean and standard deviation of respiratory rate recorded at admission, $6 \mathrm{Hrs}, 24 \mathrm{Hrs}$, $48 \mathrm{Hrs}$ in both groups

\begin{tabular}{|l|c|c|c|}
\hline \multicolumn{1}{|c|}{ SPO $^{2}$} & $\begin{array}{c}\text { Salbutamol } \\
\text { Group }\end{array}$ & $\begin{array}{c}\text { Adrenaline } \\
\text { Group }\end{array}$ & P-Value \\
\hline Admission & $92.4 \pm 2.1$ & $93 \pm 1.5$ & 0.218 \\
\hline $6 \mathrm{Hrs}$ & $93.6 \pm 1.9$ & $94.5 \pm 1.7$ & 0.06 \\
\hline $24 \mathrm{Hrs}$ & $95.3 \pm 1.4$ & $96.1 \pm 1.2$ & 0.18 \\
\hline $48 \mathrm{Hrs}$ & $96.3 \pm 1.3$ & $96.7 \pm 1.5$ & 0.17 \\
\hline
\end{tabular}

Table-VII. Mean and standard deviation of SPO ${ }^{2}$ recorded at admission, $6 \mathrm{Hrs}, 24 \mathrm{Hrs}, 48 \mathrm{Hrs}$ in both groups

\begin{tabular}{|l|c|c|c|}
\hline Heart Rate & $\begin{array}{c}\text { Salbutamol } \\
\text { Group }\end{array}$ & $\begin{array}{c}\text { Adrenaline } \\
\text { Group }\end{array}$ & P-Value \\
\hline Admission & $115 \pm 10.7$ & $107 \pm 9.2$ & 0.003 \\
\hline $6 \mathrm{Hrs}$ & $109 \pm 13.4$ & $104 \pm 8.4$ & 0.07 \\
\hline $24 \mathrm{Hrs}$ & $103 \pm 10.8$ & $99 \pm 5.5$ & 0.06 \\
\hline $48 \mathrm{Hrs}$ & $97 \pm 9.5$ & $99 \pm 6.4$ & 0.17 \\
\hline
\end{tabular}

Table-VIII. Mean and standard deviation of heart rate in both groups 


\section{DISCUSSION}

Acute viral bronchiolitis is mentioned as one of the common infections of lower respiratory tract in children younger than 2 years. Treatment of infants with bronchiolitis is usually supportive, other treatment strategies include bronchodilators, that have a controversial role in treatment of bronchiolitis, other agents including adrenaline were postulated to offer better benefit with its effect of reducing the mucosal edema and achieving satisfactory bronchodilation. ${ }^{11}$ Numerous adrenergic agonists that are both alpha and beta agonists, like metaproterenol, salbutamol and adrenaline have been used in the nebulized form for the management of bronchiolitis, but with mixed results. ${ }^{12}$

In our study there was a significant difference in the duration of hospital stay in patients treated with adrenaline nebulization as compared to salbutamol nebulization. There was a reduction in RDAl score in successive observations in both the groups, with improvement in SPO². There was also no significant difference in duration of oxygen therapy in both the groups. Adrenaline is thought to cause tachycardia; in our study also there was an increase in heart rate in both groups with successive readings. This tachycardia was observed more in adrenaline receiving group but there was a later on stabilization of heart rate in both groups at $48 \mathrm{hrs}$. No significant interventional complication was noticed in either of the two groups.

In a study performed by Gayti K et al, the results were better in the adrenaline group with significant improvement in respiratory rate, RDAl score and $\mathrm{SpO}^{2}$, decreased oxygen requirement and shorter hospital stay. ${ }^{2}$ However, in contrast, in another study Adhikari et al concluded that patients of acute bronchiolitis had no significant difference in RDAl scores whether they were nebulized with salbutamol or adrenaline. ${ }^{4}$ Simsek Kiper PO et al also performed a study for the emergency room management of acute bronchiolitis in which they compared results in terms of clinical effects, including mean respiration rate, mean oxygen saturation and severity score, and their study also did not show any statistically significant difference between nebulized salbutamol and adrenaline. ${ }^{13}$ Khashabi $\mathrm{J}$ et al concluded in their study that nebulized adrenaline and salbutamol improved oxygenation and decreased respiratory distress better than normal saline. Adrenaline was more effective in relieving respiratory distress and improving oxygen saturation as well as the need for hospitalization than nebulized salbutamol. ${ }^{14}$ The chochrane review mentioned that, when comparing adrenaline with placebo, there was no differences in the length of hospital stay but there is some indication that adrenaline is effective for decreasing the number of hospital admissions in children with bronchiolitis. More over the chochrane review authors also concluded that there was insufficient evidence to support the use of adrenaline for the treatment of bronchiolitis among hospital admitted children with bronchiolitis. ${ }^{15}$ Abdul-Ainine $A$ et al compared efficacy of adrenaline nebulization with placebo and supportive management but they concluded that no improvement was found with inhaled adrenaline in acute bronchiolitis, when compared with supportive care or placebo. However, they also mentioned their study that as adrenaline was found to have no deleterious effect on the patients it might be considered for its bronchodilator properties in infants over 1 year of age with recurrent wheeze. ${ }^{16}$

Our study has shown that adrenaline is better regarding shortening of the duration of hospital stay as compared to salbutamol. Our study favors the results of studies performed by Gayti $\mathrm{K}$ et al and Mohammad $\mathrm{RM}$ et $\mathrm{al}^{2,3}$, but in our study both adrenaline and salbutamol were equally effective in reduction of RDAl score and requirement of oxygen therapy with no significant difference in these outcomes. Adhikari et al also concluded that there was equal reduction in RDAl score when children were nebulized with either salbutamol or adrenaline. ${ }^{4}$ In our study, however, if RDAl scores were compared till the time of discharge of patients in both groups, further recommendations regarding benefit of adrenaline in reduction of RDAl scores could have been given because many children included in our study remained admitted for more than 48hrs. Further studies in this regard can be done 
to overcome this limitation. Keeping in mind the incidence of bronchiolitis, another limitation was decreased number of patients, although we had strict inclusion criteria, a study done at a broader level with increased number of patients can also improve recommendations regarding clinical improvement in terms of RDAl scores in patients admitted with bronchiolitis who are nebulized with adrenaline.

\section{CONCLUSION}

We concluded in our study that adrenaline nebulization significantly reduces the duration of hospital stay in children admitted with bronchiolitis when compared with nebulized salbutamol. There was no significant difference in RDAI scores compared between the two groups at different time intervals. Moreover, there was no significant difference between heart rate, respiratory rate, $\mathrm{SPO}^{2}$, and requirement of oxygen therapy.

Copyright $@ 15$ Mar, 2019.

\section{REFERENCES}

1. Teeranai S, Ran DG. Nebulized epinephrine for young children with bronchiolitis. Canadian family physician. 2016; 62:991-3.

2. Gayti K, KC K. Comparison of salbutamol to adrenaline nebulization in acute severe bronchiolitis: An original research paper. International Journal of Scientific Study. 2017; 5(2):202-5.

3. Mohammad RM, Asadola A, Jamal F, Mehrshad A, Firoozeh M. Comparison of epinephrine to salbutamol in acute bronchiolitis. Iran J Pediatr. 2012 Jun; 22(2): 241-4.

4. Adhikari S, Thapa P, Rao KS, BK G. Comparison of initial response of nebulized salbutamol and adrenaline in infants and young children admitted with acute bronchiolitis. Kathmandu Univ Med J 2016; $53(1): 31-5$

5. Anna C, Jonathan M, Kohei H, Peter SD, Ashley S, Janice $A$, et al. Multicenter study of albuterol use among infants hospitalized with bronchiolitis. Western Journal of Emergency Medicine. 2018 May; 19(3):475-83.
6. Gadomski AM, Scribani MB. Bronchodilators for bronchiolitis. Cochrane Database of Systematic Reviews. 2014; (6).

7. HavardOS, John OG, Sabine KB, Anne CB, Hanne $E$, Leif $E$, Marius $H$, et al. Racemic adrenaline and inhalation strategies in acute bronchiolitis. $\mathrm{N}$ Engl $\mathrm{J}$ Med. 2013; 368:2286-93.

8. Akca H, Tuygun N, Karacan CD. Nebulized epinephrine treatment in pediatric emergency department. Pediat Therapeut. 2014; 4:210.

9. Drysdale SB, Green CA, Sande CJ. Best practice in the prevention and management of paediatric respiratory syncytial virus infection. Therapeutic Advances in Infectious Disease. 2016; 3(2): 63-71.

10. Sireesha S, Prasad BS, Suresh J. Comparison of nebulized Salbutamol versus Adrenaline in the treatment of wheeze associated respiratory tract infection. Int J Contemp Pediatr. 2018 Jan; 5(1):169-72.

11. John BM, Patnaik SK, Prasad PL. Efficacy of nebulised epinephrine versus salbutamol in hospitalized children with bronchiolitis. MJAFI. 2006; 62(4): 354-7.

12. Ray MS, Singh V. Comparison of nebulized adrenaline versus salbutamol in wheeze associated respiratory tract infection in infants. Indian Pediatrics. 2002; 39: 12-22.

13. Simsek-Kiper PO, Kiper N, Hascelik G, Dolgun A, Yalcın E, Dogru- Ersoz D, et al. Emergency room management of acute bronchiolitis: A randomized trial of nebulized epinephrine. Turk J Pediatr. 2011; 53: $651-60$.

14. Khashabi J, Salarilak S, Karamiyar M, Mussavi $H$. Comparison of the efficacy of nebulized L-epinephrine, salbutamol and normal saline in acute bronchiolitis: a randomized clinical trial. Medical Journal of the Islamic Republic of Iran. 2005;19(2):11925.

15. Hartling L, Bialy LM, Vandermeer B, Tjosvold L, Johnson $D W$, Plint $A C$, et al. Epinephrine for bronchiolitis. Cochrane Database of Systematic Reviews. 2011; 6: CD003123. DOI: 10.1002/14651858.CD003123.pub3.

16. Abdul-Ainine A, Luyt $D$. Short term effects of adrenaline in bronchiolitis: A randomized controlled trial. Arch Dis Child. 2003; 86:276-79. 


\begin{tabular}{|c|l|l|l|}
\hline \multicolumn{3}{|c}{ AUTHORSHIP AND CONTRIBUTION DECLARATION } \\
\hline Sr. \# & \multicolumn{1}{|c|}{ Author-s Full Name } & Contribution to the paper & Author=s Signature \\
\hline 1 & Shehla Usman & Literature search, Write up. \\
\hline 2 & Aneela Zareen & Concetualization of study. \\
\hline 3 & Aimun Gillani & Data collection. \\
\hline 5 & Ammara Kaleem & Data analysis. \\
\hline 6 & Hussan Ali Sarwar & Proof reading.
\end{tabular}

